\title{
Study on Photooxidation and Biodegradation of Lignite
}

\author{
LI Jian-tao ${ }^{1, a}$, LIU Xiang-rong ${ }^{2, b}$, XU Yun-long ${ }^{3, c}$, ZHANG Yao-wen $^{4, d}$ \\ ${ }^{1,2,3,4}$ College of Chemistry and Chemical Engineering, Xi'an University of Science and Technology, \\ Xi'an, 710054, China \\ ${ }^{1}$ College of Chemical Engineering and Modern Materials, Shangluo University, Shangluo, Shaanxi, \\ 726000, China

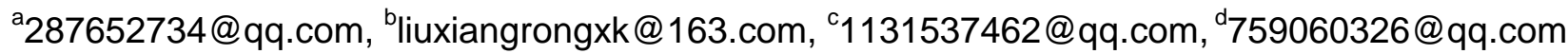

\section{Keywords: Lignite; Phanerochaete chrysosporium; Biodegradation; Photooxidation;Orthogonal optimization}

Abstract. The process conditions of phanerochaete chrysosporium degrading photo-oxidizd Inner Mongolia Shengli lignite were optimized by orthogonal test, and the effect-weight order to degradation rate was coal pulp concentration > coal particle size > incubation time > inoculum size, the optimal process conditions determined were coal particle size of $75 \sim 45 \mu \mathrm{m}$, coal pulp concentration of $0.2000 \mathrm{~g} / 20 \mathrm{~mL}$, incubation time of $14 \mathrm{~d}$ and inoculum size of $2.0 \mathrm{~mL} / 20 \mathrm{~mL}$. Under the optimal conditions, the experiment was carried out and its products were tested. The proximate and ultimate analyses of raw, photo-oxidized and residual lignite indicate that the effect of photooxidation and biodegradation both reduce the content of organic substances in lignite, and the increase of oxygen and hydrogen in residual lignite may be due to the degradation process accompanying by oxidation and hydrolysis reactions. The results of GC-MS of degradation liquid extracting by ethyl acetate are shown that the product contains 52 kinds of organic substances, molecular weight range from 67 to 759, mostly are aliphatic hydrocarbons, aldehydes, esters, carboxylic acids and aromatic compounds, which are consistent with the UV-VIS and FTIR spectra results of the products.

\section{Introduction}

From a global perspective, the energy of each country is based on fossil energy, and in primary energy, the dominants are oil, coal and natural gas. In China's energy composition, coal accounted for more than $60 \%$, and in the present and future for a long time, be with irreplaceable important position. Coal is not only the main source of energy in China, but also the main chemical raw materials ${ }^{[1-3]}$. However, the traditional coal processing technologies (Combustion for power generation, liquefaction, gasification, pyrolysis, coking and so on) have high energy consumption, large pollution, do not meet the environmental protection and energy consumption of China's sustainable development strategies, their application and development will be more and more constraints. For this reality, in energy use, both energy needs and environmental protection should be taken into account in the future ${ }^{[4-6]}$. Comparing with traditional mineral processing technologies, coal microbial transformation technology has the characteristics of simpler operation, lower cost, lower energy consumption and so on. It is also a new environment-friendly technology, which is of a smaller pollution for air, water and soil, a green and efficient way to use mineral resources ${ }^{[7-8]}$.

Coal microbial transformation refers to the depolymerization of coal macromolecules under the role of microorganisms, usually can be called coal biodegradation or coal biodissolution or coal bioconversion. This technology is mainly the use of fungi, bacteria and actinomycetes on the transformation of coal to make the coal dissolution-degradation, liquefaction or gasification into a water-soluble substances or hydrocarbon gases, from which a special value chemicals, clean fuels, industrial additives and plant growth promoters are produced ${ }^{[9-10]}$. This processing technology is a new type of coal conversion method, especially, is of great significance for the transformation and efficient use of low-quality coal samples, such as lignite and low-quality bituminous coal ${ }^{[11]}$. 
In addition, most of the newly mined coal is not conducive to microbial degradation, but the coal which exposure to air for a period of time is more susceptible to microbial degradation, that because the weathered coal has a higher oxygen content. Therefore, the coal generally is pretreated by oxidation before microbial degradation, and pretreatment of nitric acid oxidation is the most reported in the literature ${ }^{[12]}$. However, the nitric acid oxidation method damages the structure of coal violently, increases the content of nitrogen in coal, if it eventually uses as fuel, would increase the emissions of nitrogen compounds, and cause environment pollution. Furthermore, the nitric acid oxidation of coal need a lot of water to washed it to near neutral $\mathrm{pH}$ in order to carry out subsequent microbial transformation, this process requires not only a lot of water resources but also is terrible to environmental protection and safety ${ }^{[13]}$. Thus, this study used a rotary bed photochemical reactor to pretreat coal samples, and then carry out microbial transformation. The photooxidation pretreatment is superior to nitric acid oxidation in terms of environmental protection, safety and operability.

In this study, the degradation of photo-oxidized Inner Mongolia Shengli lignite by Phanerochaete chrysosporium was carried out to determine the optimum conditions and then test and analyze the degradation products.

\section{Materials and methods}

Lignite sample. The lignite used in this study was sampled from Inner Mongolia Shengli coal field. It was crushed, blended with photocatalyst (amphiphilic nano- $\mathrm{TiO}_{2}$ ) for a mass ratio of 1: 0.002, grinded using ball mill, and then sieved to three fragments that particle size were 180 106 $\mu \mathrm{m}$, 106 75 $\mu \mathrm{m}$ and 75 45 $\mu \mathrm{m}$.

Fungal strain and source. The experimental strain was phanerochaete chrysosporium purchased from China General Microbiological Culture Collection Center (CGMCC).

Medium and composition. Fungal growth medium selected SDA medium, degradation medium selected improved PDA medium, their compositions were in Tables 1 and 2.

Table 1 Composition of SDA medium

\begin{tabular}{|c|c|c|c|c|c|c|c|c|}
\hline Composition & \multicolumn{2}{|c|}{ Maltose } & \multicolumn{2}{|c|}{ Peptone } & \multicolumn{2}{|c|}{ Ultrapure water } & \multicolumn{2}{|r|}{ Agar(solid) } \\
\hline Content & \multicolumn{2}{|c|}{$200 \mathrm{~g}$} & \multicolumn{2}{|c|}{$20 \mathrm{~g}$} & \multicolumn{2}{|c|}{$1 \mathrm{~L}$} & & $15-20 \mathrm{~g}$ \\
\hline \multicolumn{9}{|c|}{ Table 2 Composition of improved PDA medium } \\
\hline Composition & Potato extract & Glucose & $\mathrm{KH}_{2} \mathrm{PO}_{4}$ & $\mathrm{MgSO}_{4}$ & $\mathrm{FeSO}_{4}$ & $\mathrm{CuSO}_{4}$ & $\mathrm{VB}_{1}$ & Ultrapure water \\
\hline Content & $200 \mathrm{~g}$ & $20 \mathrm{~g}$ & $3 \mathrm{~g}$ & $1.5 \mathrm{~g}$ & $1 \mathrm{mg}$ & $2 \mathrm{mg}$ & $8 \mathrm{mg}$ & $1 \mathrm{~L}$ \\
\hline
\end{tabular}

Photooxidation pretreatment of lignite. Lignite samples were treatment using a rotary bed photochemical reactor for $24 \mathrm{~h}$, with UV lamps power of 120 watts, rotation bed speed at $60 \mathrm{r} / \mathrm{min}^{[14]}$.

Fungal resurrection. Lignite samples and all the equipments were sterilized before operation. A little phanerochaete chrysosporium colony preserved by slope at $4{ }^{\circ} \mathrm{C}$ in refrigerator was put into conical flask with $20 \mathrm{~mL}$ SDA medium and several glass beads in it, shaking the flask violently. Then the fungi liquid was inoculated to the plate dishes by coated plate method. After that the dishes were placed in an artificial climate incubator at $28{ }^{\circ} \mathrm{C}$ and a relative humidity of $80 \%$ until the culture dishes were covered with fungi moss. So inoculated and cultured repeatedly for three generations preparing for the subsequent lignite degradation experiments.

Liquid dissolution experiment of lignite. Taking a diameter of $5 \mathrm{~mm}$ fungi moss from the well resurrected fungi dish into a conical flask with $20 \mathrm{~mL}$ PDA medium and several glass beads, shaking violently, and then the fungi liquid was filtered using a sterile stainless steel mesh to remove the cells, and a parent fungi liquid was obtained. Conical flask with 20 mL PDA medium was inoculated by an inoculation ring dipping in the parent liquid, after two days culture in the incubator, coal samples were added into the flask for degradation experiments. Each experiment was done in three parallels while making a blank control (without fungi).

In the end of the experiment, the degradation filtrate was taken and diluted 100 times and tested the absorbance at a wavelength of $450 \mathrm{~nm}$, the absorbance of original filtrate was the value tested multiplied by the dilution factor of 100 . The three absorbance values of the original degraded liquid were averaged as an index of the degradation effect ${ }^{[15-16]}$. 
Orthogonal test design. Based on the results of previous single factor tests, the orthogonal table $L_{9}\left({ }_{3}{ }^{4}\right)$ was used to design the technological conditions for the degradation of photo-oxidized lignite by Phanerochaete chrysosporium, presented in table 3. The main influence factors to biodegradation were as follows: coal particle size, coal slurry concentration, incubation time and inoculum size, each factor took three levels and regardless of the interactions between them. The incubator temperature was set up at $28{ }^{\circ} \mathrm{C}$ and the oscillation speed was $160 \mathrm{r} / \mathrm{min}$ according to the single factor tests. The experimental method was like "Liquid dissolution experiment of lignite" before.

Table 3 Orthogonal table design of $L_{9}\left({ }_{3}{ }^{4}\right)$

\begin{tabular}{ccccc}
\hline \multirow{2}{*}{ Levels } & \multicolumn{3}{c}{ Factors } \\
\cline { 2 - 5 } & A-Coal particle size $[\mu \mathrm{m}]$ & B-coal pulp concentration $[\mathrm{g} / 20 \mathrm{~mL}]$ & C-incubation time $[\mathrm{d}]$ & D-inoculum size $[\mathrm{mL} / 20 \mathrm{~mL}]$ \\
\hline 1 & $180 \sim 106$ & 0.1500 & 12 & 1.8 \\
2 & $106 \sim 75$ & 0.2000 & 14 & 2.0 \\
3 & $75 \sim 45$ & 0.2500 & 16 & 2.2 \\
\hline
\end{tabular}

\section{Results and discussion}

Analysis of orthogonal test results. Table 4 showed the orthogonal test results of Phanerochaete chrysosporium degrading photo-oxidized Inner Mongolia Shengli lignite. Comparing the four ranges of the factors with each other in the table, we could see that the effect-weight order are as follows: B > $\mathrm{A}>\mathrm{C}>\mathrm{D}$, and among the four factors, the coal pulp concentration has the greatest influence on the degradation of lignite, followed by the coal particle size and inoculum size has the least.

Table 4 Orthogonal test results of Phanerochaete chrysosporium degrading lignite

\begin{tabular}{|c|c|c|c|c|c|}
\hline \multirow{2}{*}{ Serial number } & \multicolumn{4}{|c|}{ Factors } & \multirow{2}{*}{$A_{450}$} \\
\hline & $A$-Coal particle size & $B$ - Coal pulp concentration & $C$-Incubation time & $D$ - Inoculum size & \\
\hline 1 & 1 & 1 & 1 & 1 & 26.652 \\
\hline 2 & 1 & 2 & 2 & 2 & 27.980 \\
\hline 3 & 1 & 3 & 3 & 3 & 20.256 \\
\hline 4 & 2 & 1 & 2 & 3 & 34.353 \\
\hline 5 & 2 & 2 & 3 & 1 & 33.115 \\
\hline 6 & 2 & 3 & 1 & 2 & 22.637 \\
\hline 7 & 3 & 1 & 3 & 2 & 38.439 \\
\hline 8 & 3 & 2 & 1 & 3 & 35.768 \\
\hline 9 & 3 & 3 & 2 & 1 & 28.351 \\
\hline$K_{1}$ & 24.963 & 33.148 & 28.352 & 29.373 & \\
\hline$K_{2}$ & 30.035 & 32.288 & 30.228 & 29.685 & \\
\hline$K_{3}$ & 34.186 & 23.748 & 30.603 & 30.126 & \\
\hline$R$ & 9.223 & 9.400 & 2.251 & 0.753 & \\
\hline
\end{tabular}

In addition, on the basis of the three mean values of the absorbance $K 1, K 2$, and $K 3$ corresponding to each factor, the optimal combination of process conditions obtained is $A_{3} B_{1} C_{3} D_{3}$. After comparison, it is found that $K 2$ and $K 3$ are not very different for $\mathrm{C}$-incubation time and $\mathrm{D}$-inoculation size, we can try $\mathrm{A}_{3} \mathrm{~B}_{1} \mathrm{C}_{2} \mathrm{D}_{2}$ for experiments considering the economic principle. Then the combination of $\mathrm{A}_{3} \mathrm{~B}_{1} \mathrm{C}_{2} \mathrm{D}_{2}$ was carried out according to the method of "Liquid dissolution experiment of lignite", and the average absorbance was calculated to be 37.856, which was close to the highest absorbance of 38.439 in the orthogonal table. So the combination of $\mathrm{A}_{3} \mathrm{~B}_{1} \mathrm{C}_{2} \mathrm{D}_{2}$ was determined as the optimum technological conditions, namely, particle size of $75 \sim 45 \mu \mathrm{m}$, coal pulp concentration of $0.2000 \mathrm{~g} / 20$ $\mathrm{mL}$, incubation time of $14 \mathrm{~d}$ and inoculum size of $2.0 \mathrm{~mL} / 20 \mathrm{~mL}$.

Proximate and ultimate analysis. Proximate and ultimate analysis results of raw, photo-oxidized and residual lignite were presented in Table 5. From the proximate analysis of raw and photo-oxidized lignite, it can be seen that the water content of the photo-oxidized is higher than that of the raw lignite, which indicate that the water absorption of the photo-oxidized is stronger than that of the raw lignite. Ash content increase, volatile and fixed carbon decreases indicate that the organic substances content of lignite decreased after the photooxidation pretreatment. Comparing the ultimate analysis of the two with each other, it is found that the contents of $\mathrm{C}, \mathrm{H}, \mathrm{N}$ and $\mathrm{S}$ in the photo-oxidized are lower than in the raw lignite and the oxygen content is increased, which show that the raw lignite is oxidized and photo-degraded under the combined actions of light, photocatalyst and oxygen in the air. 
Comparing the ultimate analysis of photo-oxidized lignite and residual lignite with each other, it can be seen that the moisture absorption of residual lignite is lower than that of photo-oxidized lignite. The increase of ash content, decreases of volatile and fixed carbon indicate that the organic substances in the photo-oxidized lignite are further degraded into a soluble substance dissolving in the degradation solution or producing a gas molecule to escape. The ultimate analysis results of the photo-oxidized and residual lignite show that the contents of $\mathrm{C}, \mathrm{N}$ and $\mathrm{S}$ in residual lignite are reduced, and the organic substances of lignite may be degraded or utilized to produce soluble substances or gas molecules, this is consistent with the results of proximate analysis. The further increase of $\mathrm{H}$ and $\mathrm{O}$ contents probably because the degradation process may be accompanied by oxidation and hydrolysis reactions, so that the oxygen in air or hydrogen and oxygen of water are taken into the system ${ }^{[17]}$.

Table 5 Proximate and ultimate analyses of raw, photo-oxidized and residual lignite

\begin{tabular}{cccccccccc}
\hline \multirow{2}{*}{ Coal samples } & \multicolumn{3}{c}{ proximate analysis $(\mathrm{ad}) w t \%$} & \multicolumn{4}{c}{ Ultimate analysis $(\mathrm{ad}) w t \%$} \\
\cline { 2 - 10 } & $M$ & $A$ & $V$ & $F C$ & $\mathrm{C}$ & $\mathrm{H}$ & $\mathrm{N}$ & $\mathrm{S}$ & $\mathrm{O}$ \\
\hline Raw lignite & 12.04 & 9.78 & 25.14 & 53.04 & 57.54 & 4.80 & 0.65 & 0.68 & 14.54 \\
Photo-oxidized lignite & 14.76 & 11.28 & 21.57 & 52.39 & 52.08 & 3.27 & 0.62 & 0.42 & 17.79 \\
Residual lignite & 11.86 & 18.73 & 18.62 & 50.79 & 42.82 & 5.23 & 0.51 & 0.27 & 20.58 \\
\hline
\end{tabular}

UV-VIS spectrum of liquid product. Experiment was done according to the optimal degradation process, and the degradation liquid product was filtrated and diluted 100 times, and then the absorbance of diluted liquid at 200-600nm was scanned by PERSEE TU-900 ultraviolet spectrophotometer shown in Fig.1. It can be seen that UV-VIS spectrum of the liquid product had two strong absorption peaks at $250-290$ and $300-370 \mathrm{~nm}$. The strong absorption at $250-290 \mathrm{~nm}$ is the characteristic absorption peak of aromatic ring, which is a benzene ring B absorption band with fine structure. Another strong absorption peak at 300-370 nm indicates that the product contains aldehyde, ketone carbonyl or Conjugated carbonyl, where the absorption peak is the unsaturated aldehydes and ketones of the $\mathrm{R}$ absorption band, probably due to the fungal degradation of coal product contains unsaturated aldehydes and ketones.

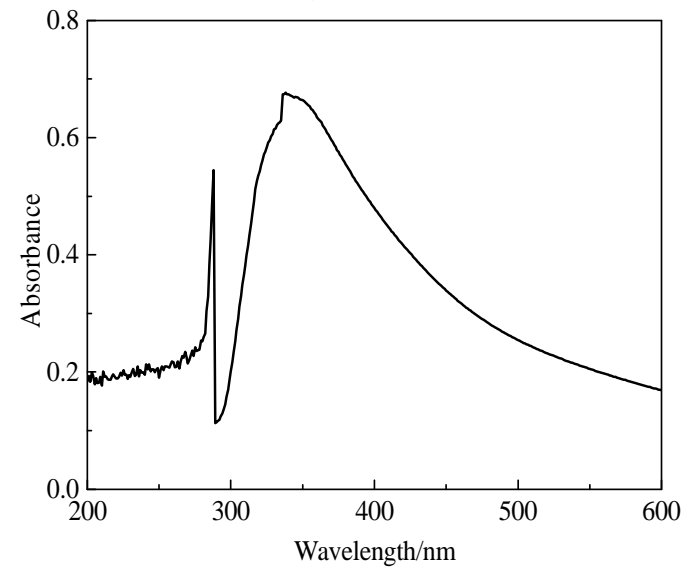

Fig.1 UV-VIS spectrum of liquid product

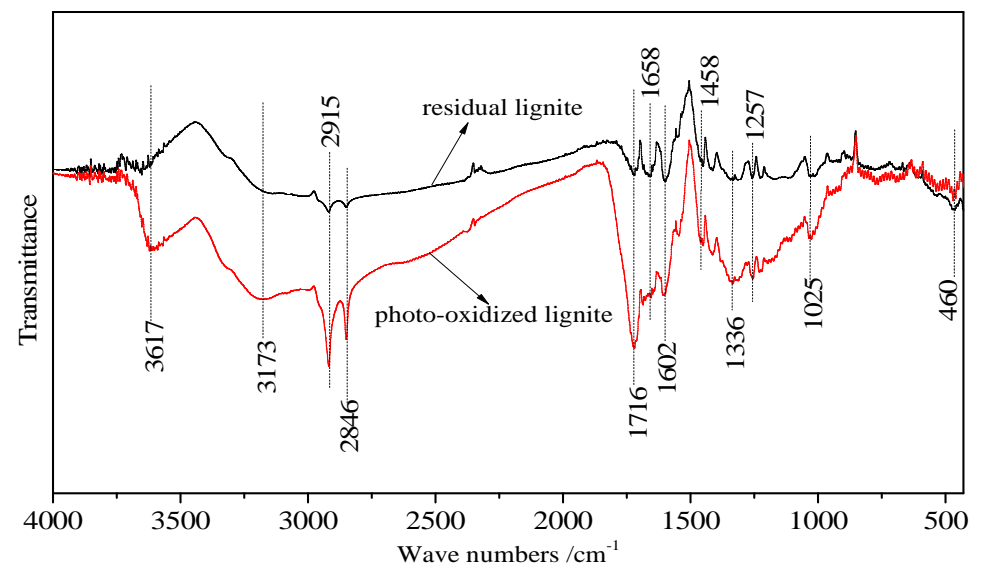

Fig.2 FTIR spectra of photo-oxidized and residual lignites

FTIR spectra of photo-oxidized and residual lignite. The same amount of photo-oxidized and residual lignite were weighed by analytical balance and mixed with equal amount of Potassium bromide (KBr), respectively, and infrared detection was carried out by $\mathrm{KBr}$ tabletting method using Perkin Elmer's Spectumn GX-type Fourier infrared spectrometer, spectra were shown in Fig.2. Compared with the two spectra, it was found that the absorption peaks of residual lignite were weakened at the corresponding absorption peaks of photo-oxidized lignite, and it can infer that the photo-oxidized lignite was degraded by Phanerochaete chrysosporium.

The main absorption peaks of photo-oxidized and residual lignite at 3617 and $3173 \mathrm{~cm}^{-1}$ corresponding to the stretching vibration of $\mathrm{O}-\mathrm{H}$ indicate that the photo-oxidized lignite contains alcohols, phenols or organic acids. Peaks at 2915 and $2846 \mathrm{~cm}^{-1}$ are corresponding to the stretching vibration absorption of $\mathrm{CH}_{2}$. Peaks are observed at $1900-1850 \mathrm{~cm}^{-1}$ corresponding to the vibration absorption of $\mathrm{C}=\mathrm{O}$ indicating the presence of aldehydes, ketones, carboxylic acids, esters and anhydrides. In particular, the bimodal at $1716 \mathrm{~cm}^{-1}$ and $1658 \mathrm{~cm}^{-1}$ indicate the presence of the 
associative anhydride of the carboxylic acid. The bimodal near 1600 and $1500 \mathrm{~cm}^{-1}$ are the aromatic ring connected to the chain containing $\mathrm{C}=\mathrm{C}$ conjugate structure of the skeleton vibration. Peaks at $1300-1000 \mathrm{~cm}^{-1}$ are the stretching vibration absorption of $\mathrm{C}-\mathrm{O}$. The absorption peaks around $1000-400 \mathrm{~cm}^{-1}$ are the out-of-plane stretching vibration absorption of the $\mathrm{C}-\mathrm{C}$ bond on the aromatic ring $^{[18]}$.

GC/MS ions chromatogram of degradation liquid products. The degradation liquid products under optimum conditions were filtered and the resulting black oily liquid was filtered through a 0.22 $\mu \mathrm{m}$ microporous membrane and then extracted with ethyl acetate, the resulting extract was tested using an Agilent 7890A/5975C Gas Chromatography-Mass Spectrometer (GC/MS) equipped with a capillary column coated with HP-5MS(crosslink 5\% PH ME siloxane, $30 \mathrm{~m} \times 0.25 \mathrm{~mm}$ i.d., $0.25 \mathrm{~lm}$ filmthickness) and a quadrupole analyzer and operated in electron impact $(70 \mathrm{eV})$ mode. The mass range scanned was from 30 to $500 \mathrm{amu}^{[19-20]}$. The results was presented in Fig.3.

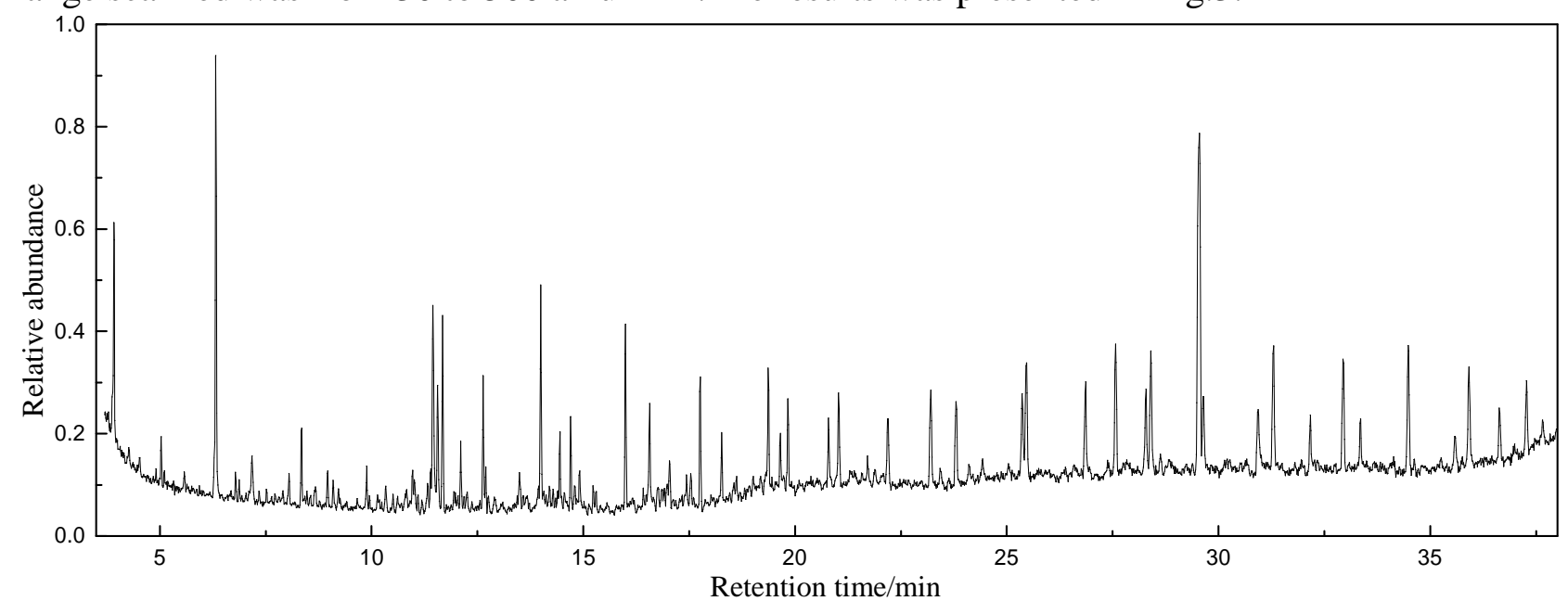

Fig. 3 Total ion chromatogram of ethyl acetate extracting degradation liquid products

Experimental data were acquired and processed using Chemstation. The compounds were identified by comparing with NIST library data. Ethyl acetate extraction product mainly contains 52 kinds of organic substances, molecular weight range from 67 to 759, mostly are aliphatic hydrocarbons, aldehydes, esters, carboxylic acids and aromatic compounds. Combining with UV-VIS and FTIR spectra, it can be deduced that the effect of Phanerochaete chrysosporium degrading photo-oxidized lignite is outstanding and the degradation products are rich in organic micromolecules.

\section{Conclusions}

(1) On the basis of single factor tests, process conditions of phanerochaete chrysosporium degrading photooxidizd Inner Mongolia Shengli lignite were optimized by orthogonal test, and the effect-weight order to degradation rate inferred was coal pulp concentration > coal particle size > incubation time > inoculum size, the optimal process conditions were coal particle size of $75 \sim 45 \mu \mathrm{m}$, coal pulp concentration of $0.2000 \mathrm{~g} / 20 \mathrm{~mL}$, incubation time of $14 \mathrm{~d}$, inoculum size of $2.0 \mathrm{~mL} / 20 \mathrm{~mL}$.

(2)Proximate and ultimate analyses of raw, photo-oxidized and residual lignite show that photooxidation improve the water absorption and oxygen content of lignite, which would be beneficial to the degradation of lignite by fungi. The effects of photooxidation and Phanerochaete chrysosporium on lignite reduce the amount of organic subustances in lignite, and the further increase of $\mathrm{H}$ and $\mathrm{O}$ contents probably because the process of degradation might be accompanied by oxidation and hydrolysis reactions.

(3)The GC/MS analysis results of degradation liquid extracting by ethyl acetate are shown that the product containes 52 kinds of organic substances, molecular weight range from 67 to 759, mostly are aliphatic hydrocarbons, aldehydes, esters, carboxylic acids and aromatic compounds, which are consistent with the UV-VIS and FTIR spectra of the products. 


\section{Acknowledgements}

This work was financially supported by the National Natural Science Foundation of China (21373158) and Shaanxi science and technology agency of sino-australian cooperation projects (2013KW17).

\section{References}

[1] TENG Ji-wen, ZHANG Xue-mei, YANG Hui. Exploration and exploitation in second deep space of crust interior and high efficient utilization of the major energy — coal resource in China[J]. Progress in Geophysics, 2008, 23(4):972-992.

[2] CHEN Yin-ying, WANG Shu-juan, CHEN Chang-he, et al. Study on high efficient and clean utilization of coal[J]. Engineering Sciences, 2011, 13(6):51-55.

[3] LI Zhong-min. The status of coal in the world's energy consumption structure[J]. China Coal, 2006, 32(8):81-82.

[4] ZHANG Dong-chen. The development of modern mining biological technology and its application in coal processing[J]. China Coal, 2006, 32(3):51-54.

[5] YUAN Hong-li, CHEN Wen-xin. Coal liquidation by Microorganisms[J]. Microbiology China, 1997, 24(5):284-286.

[6] LI Hong-yan. Application and Development prospect of Environmental Biotechnology[J]. China Environmental Protection Industry, 2006 (11):8-11.

[7] AN Sheng-jie, SUN Chang-yun. Consideration on China National Coal Clean Utilization Base on Clean Rate[J]. Coal Economic Research, 2012, 32(9):40-43.

[8] Fakoussa, Hofrichter. Minireview microbiology and biotechnology of coal degradation[J]. Applied Microbial Technology, 1999, 52: 25-40.

[9] WANG Long-gui, ZHANG Ming-xu, OU Zen-shen, et al. Experimental of coal biodegradation by white rot fungus[J]. Journal of China Coal Society, 2006, 31(2): 241-244.

[10] WANG Jing. Experimental study on microbial degradation of BaoJi Linyou long flame coal[D]. Xi'an, Xi'an University of Science and Technology, 2016.

[11]Lerato M. Sekhohola, Eric E. Igbinigie, A. Keith Cowan. Biological degradation and solubilisation of coal[J]. Biodegradation, 2013, 24:305-318.

[12]M. J. Ghani, M. I. Rajoka, Kalsoom Akhtar. Investigations in fungal solubilization of coal: mechanisms and significance[J]. Biotechnology and Bioprocess Engineering, 2015, 20:634-642.

[13] WANG Yong-juan, LI Hui, ZHANG Ya-ting, et al. Bioconversion of photo-oxidation pretreated Shenfu coal by T.versicolor[J]. Journal of China Coal Socity, 2008, 33(11): 1305-1308.

[14]LI Jian-tao, LIU Xian-grong, CAI Hui-wu, et al. Laboratory rotary bed photochemical reactor, China patent, ZL201621380305.0. (2017).

[15]Celal F.Gokcay, Nazif Kolankaya, Filiz B. Dilek. Microbial solubilization of lignites[J]. Fuel, 2001, 80:1421-1433.

[16]A. V. Selvi, Rintu Banerjee, L. C. Ram, et al. Biodepolymerization studies of low rank Indian coals[J]. World J Microbiol Biotechnol, 2009, 25:1713-1720.

[17]Helena Machnikowska, Kamila Pawelec, Anna Podgórska. Microbial degradation of low rank coals[J]. Fuel Processing Technology 2002, 77-78:17-23.

[18]BAO Yuan, JU Yi-wen, WEI Chong-tao, et al. Infrared spectrum studies of hydrocarbon generation and structure envolution of peat samples during pyrolysis and microbial degradation[J]. Spectroscopy and Spectral Analysis, 2015, 35(3): 603-608.

[19]JIANG Feng, LI Zhao-hu, LV Zhi-wei, et al. The biosolubilization of lignite by Bacillus sp.Y7 and characterization of the soluble products[J]. Fuel, 2013, 103:639-645.

[20] YAO Jing-hua. XIAO Lei, WANG Li-qiang. Separation and analysis of lignite bioconversion products[J]. International Journal of Mining Science and Technology, 2012, 22:529-532. 